\title{
Effects of a web based decision aid on parental attitudes to MMR vaccination: a before and after study
}

\author{
Cate Wallace, Julie Leask, Lyndal J Trevena
}

\begin{abstract}
Objective To determine whether an evidence based decision aid on the measles, mumps, and rubella (MMR) vaccine changed parents' attitudes towards vaccination.

Design Before and after study.

Setting Website promoted through search engines and online parenting and health websites.

Participants 158 people completing online questions out of 1277 who accessed the website.

Intervention Evidence based decision aid with text and graphical representation of the possible outcomes of measles, mumps, and rubella diseases compared with MMR vaccination. Main outcome measures Attitudes towards MMR vaccination. Results Significantly more participants indicated they were "leaning towards" vaccination after using the decision aid $(39 \%$ before $v 55 \%$ after, $\mathrm{P}<0.001)$. Compared with those who were undecided or "leaning away from" vaccination after using the decision aid, participants "leaning towards" it were more likely to strongly value its potential to protect their children from the serious side effects of disease $(98 \% v 84 \%)$ and other children who could not be vaccinated for medical reasons $(68 \% v 25 \%)$. Participants with an unfavourable attitude to vaccination were more likely to be very concerned about the rare side effects of vaccination $(78 \% v 57 \%)$, have residual concerns about autism and bowel disease $(78 \% v 27 \%)$, and anticipate guilt should their child have an adverse reaction $(77 \% v 50 \%)$. Those with a positive attitude to vaccination after using the decision aid were also more likely to feel well informed $(83 \% v 48 \%)$.

Conclusions A web based decision aid significantly improved parental attitudes to MMR vaccination. Residual concerns about autism and bowel disease and the rare chance of serious complications remained as attitudinal barriers to some parents.
\end{abstract}

\section{Introduction}

The controversy over the alleged association between autism and the combined measles, mumps, and rubella vaccine (MMR) has led to declining coverage and resultant disease outbreaks in the United Kingdom and Ireland. ${ }^{12}$ In countries such as Canada, the United States, New Zealand, and Australia many parents have also expressed concern over the safety of the vaccine, which, as shown by the UK experience, may rapidly threaten immunisation targets and disease control should this concern translate into behaviour.

There have been concerted efforts to address parental concerns about the MMR vaccine, with brochures, fact sheets, and websites designed to inform parents of the facts. Yet there is only limited evidence that providing didactic information has alleviated parents' concerns and changed their attitudes towards the vaccine. Despite the abundance of information, parents have reported they believe the information they have received is inadequate, biased, or inaccurate and have routinely requested more detailed information about the risks and benefits of the vaccine..$^{3-6}$

This apparent contradiction between the available information and parents' perception of its veracity may indicate a need to change communication strategies-rather than viewing parents as "blank slates" on which information is imprinted, we should acknowledge the critical and social context in which they interpret messages. ${ }^{7}$ An effective public health response must be relevant and responsive to parental values and preferences, engage with parents as decision makers, and endeavour to transform their views collaboratively as opposed to dictating their choices coercively. ${ }^{8}$

Decision aids may serve this purpose. They are designed to help people understand their options and potential outcomes, to consider the possible benefits and harms of their choices, and to increase consumer participation in decision making. ${ }^{9}$ They typically include probabilistic information in numerical and graphical format, information about the potential outcomes of each choice, and exercises to clarify values. Decision aids have been shown to reduce decisional conflict, improve knowledge, and change behaviours. ${ }^{9}$ However, few studies have applied them to immunisation, ${ }^{10}$ and no studies of decision aids for MMR vaccination have been published.

We report on a pilot study of an interactive, web based decision aid for parents questioning MMR vaccination. Our aim was to assess the feasibility of a larger randomised trial of effectiveness of the decision aid. Our primary interest was whether the decision aid could improve attitudes to MMR immunisation. The internet provides a previously unexplored environment for assessing the effect of a decision aid about MMR vaccination. Firstly, it may capture those who do not usually approach their healthcare provider until the immunisation decision has been made. Secondly, parents navigating cyberspace routinely encounter competing, and often controversial and highly emotive, information on which to base their decisions. ${ }^{11}{ }^{12}$ Finally, the online format allows the aid to be interactive, which also allows for the expedient collection of data from respondents.

\section{Methods}

Decision aid development

We developed the pilot MMR decision aid in the first two months of 2004. It was designed to comply, as much as possible, with the CREDIBLE criteria as defined by the Cochrane Review of Deci- 


\section{The MMR Decision Aid}

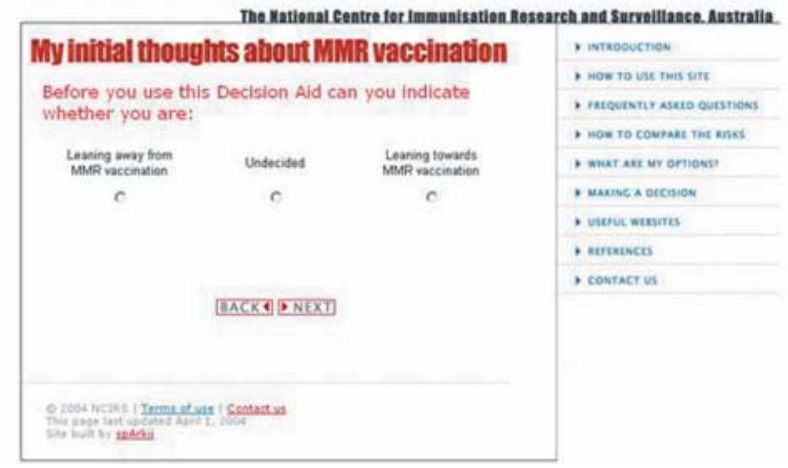

Fig 1 Screen from MMR vaccination decision aid: direction of leaning about vaccination

sion Aids. ${ }^{9}{ }^{13}$ The aid provided numerical and graphical evidence of the risks associated with the diseases, alongside the potential risks associated with the vaccine, and provided references for these estimates. We used Australian data where possible, supplemented with evidence from large international epidemiological studies, systematic reviews, and meta-analyses.

Frequently asked questions were addressed, including information about the alleged association between autism and MMR vaccination. The aid listed some key advantages and disadvantages of MMR vaccination, and users were asked to rate the importance of these on a three point scale ("Very important to me," "Slightly important to me," and "Not important to me"). Users were also asked to rate their attitudes to MMR vaccination, both before using the decision aid and again afterwards, on a three point scale ("Leaning away from MMR vaccination," "Undecided," and "Leaning towards MMR vaccination"). After using the decision aid, users' information requirements for decision making were assessed with four questions (see table 2) on a three point scale ("Yes," "Unsure," and "No").

The aid was written for a reading age of 12 years. We consulted a range of stakeholders about its content, design, and layout, including immunisation and decision aid experts, health professionals, and parents. The aid was located via the website of the Australian National Centre for Immunisation Research and Surveillance (NCIRS) at www.ncirs.usyd.edu.au/decisionaid (figs 1 and 2 show two sample screens from the aid).

\section{Recruitment}

After ethical approval of our study, the decision aid was advertised on a popular parenting website and a small number of government and parent-friendly websites, mainly in Australia and New Zealand. The decision aid went live on 20 April 2004, and data collection closed on 31 January 2005.

\section{Study design and outcomes}

Respondents had open access to the decision aid, which was designed for sequential movement through its 21 screens but with the option to move to any section via a menu. Respondents completed online questions in a stepwise fashion using radio buttons and free text but could proceed without completing questions if they chose. At the end of the aid, respondents were asked to complete demographic details. Using a before and after design, the primary outcome was change in attitude towards the MMR vaccine.

\section{Data analysis}

Respondents' attitudes were coded as -1 for "leaning away from," 0 for "undecided," and 1 for "leaning towards" vaccination. We

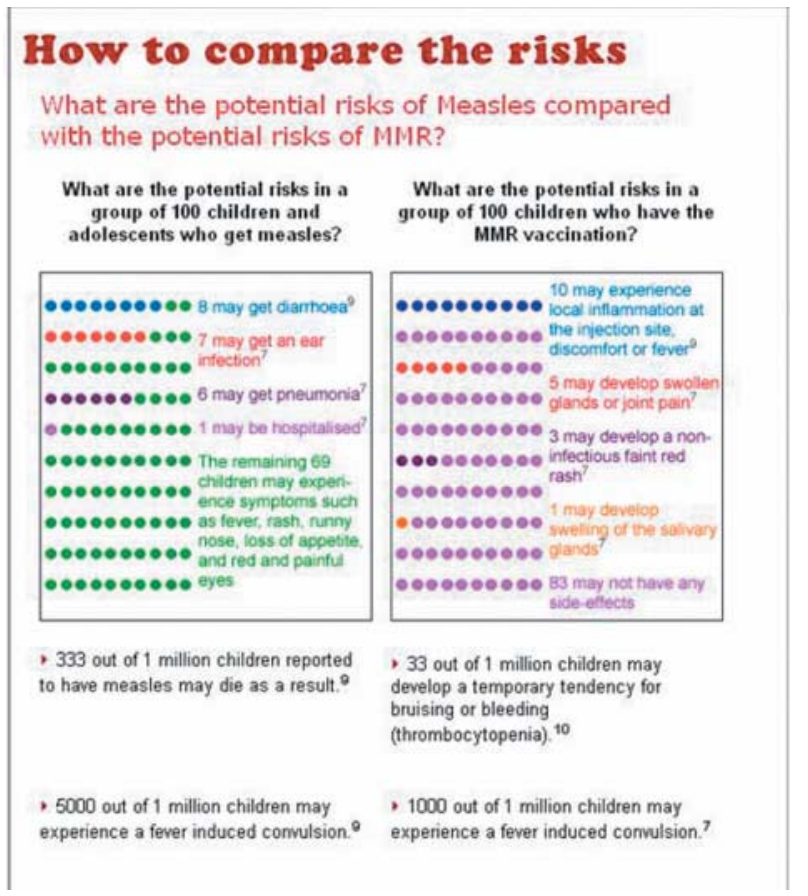

Fig 2 Screen from MMR vaccination decision aid: comparison of risks

calculated respondents' mean score before and after they viewed the aid. We used Wilcoxon's matched pairs signed ranking test (by means of SPSS version 11.5) to determine whether the change in these scores was significant. We cross tabulated each respondent's "leaning" before using the aid against their "leaning" after using the aid. This allowed identification of the number of people who were less favourably or more favourably disposed to the MMR vaccine after using the aid, and the number whose opinion was unaltered.

We dichotomised respondents' perceived importance of the advantages and disadvantages of MMR vaccination as "very important" or other ("slightly important" and "not important" combined). We compared ratings for each advantage and disadvantage with respect to whether respondents were leaning towards MMR vaccination or staying undecided or leaning away from vaccination after viewing the decision aid. We also measured the extent to which people with favourable and unfavourable attitudes to MMR vaccine perceived that their information needs had been met.

\section{Results}

\section{Respondents' characteristics}

A total of 1277 people accessed the site, with 158 completing the aid by providing responses to set questions. Of these 158 respondents, $62(39 \%)$ supplied demographic information: 55 were parents, 52 with children aged less than 5 years; 53 were aged between 25 and 44 years; and 39 had a university degree. In addition, 42 were from Australia, with the remainder from New Zealand, then the US, UK, Canada, Europe, and Asia. Thirty nine respondents were prepared to be contacted for follow-up by email or telephone.

\section{Attitudes to MMR before and after decision aid}

Table 1 shows changes in the 158 respondents' leanings before and after using the decision aid: 48 shifted in a positive direction towards MMR vaccination, and the proportion of respondents "leaning towards" MMR vaccination increased significantly from 
Table 1 Changes in attitudes to MMR vaccination among 158 respondents after use of a web based MMR decision aid. Values are numbers of respondents

\begin{tabular}{lccc} 
Attitudes to vaccination & \multicolumn{3}{c}{ Attitudes to vaccination after using decision aid* } \\
\cline { 2 - 4 } before using decision aid & $\begin{array}{c}\text { "Leaning away } \\
\text { from" }(\mathbf{n}=\mathbf{3 0})\end{array}$ & $\begin{array}{c}\text { "Undecided" } \\
(\mathbf{n}=\mathbf{4 1})\end{array}$ & $\begin{array}{c}\text { "Leaning towards" } \\
(\mathbf{n}=\mathbf{8 7})\end{array}$ \\
\hline "Leaning away from" $(\mathrm{n}=42)$ & $22 \dagger$ & $15 \ddagger$ & $5 \ddagger$ \\
\hline "Undecided" $(\mathrm{n}=55)$ & $5 \S$ & $22 \dagger$ & $28 \ddagger$ \\
\hline "Leaning towards" $(\mathrm{n}=61)$ & $3 \S$ & $4 \S$ & $54 \dagger$ \\
\hline
\end{tabular}

*Wilcoxon's matched pairs signed ranking test for change in preference was significant $(Z=-4.07, P<0.0001)$

†Participants whose opinion remained unaltered $(n=98)$

†Participants more favourably disposed to MMR vaccination after using the decision aid $(\mathrm{n}=48)$.

$\S$ Participants less favourably disposed to MMR vaccination after using the decision aid $(n=12)$.

$61(39 \%)$ before using the aid to $87(55 \%)$ afterwards $(\mathrm{P}<0.0001)$.

\section{Beliefs about MMR vaccination}

Table 2 shows respondents' views of a list of advantages and disadvantages of MMR vaccination according to whether they reported a positive attitude towards vaccination or a negative or undecided attitude. As might be expected, participants with a positive attitude towards MMR vaccination were more likely to perceive all of the listed advantages of MMR as important to them than those who remained undecided or were "leaning away from" vaccination. They were also less likely to perceive rare but serious side effects of vaccination as being important and were less likely to have residual concerns about autism and bowel disease.

The most important perceived advantage of MMR vaccination among those with a positive attitude was protection against the serious symptoms of measles, mumps, and rubella $(98 \%$ rated this as "very important," compared with $84 \%$ of those with a negative or undecided attitude). Other advantages that most respondents with a positive attitude considered very important were the protection of other children who could not be vaccinated for medical reasons $(68 \%$, versus $25 \%$ of those with negative or undecided attitudes) and protection against common symptoms of measles, mumps, and rubella (63\%, v 30\%).

Participants who remained "undecided" or "leaning away from" vaccination after using the aid were more likely to consider the disadvantages of MMR vaccination as very important, particularly the chance of rare but serious complications $(78 \%, v$ $57 \%$ of those "leaning towards" vaccination), residual concerns about autism and bowel disease (78\%, $v 27 \%)$, and fear of feeling guilty or responsible should their child have an adverse reaction to the vaccine $(77 \%, v 50 \%)$. Other reasons that respondents cited in the free text box for not getting their child vaccinated included concern over mercury in vaccines, interest in alternative types of disease prevention, family experience of serious complications (including autism and inflammatory bowel disorders), and previous adverse reactions.

Among all respondents, perceived disadvantages of MMR vaccination included the unproved link between MMR vaccination, bowel disease, and autism $(50 \%$ considered it "very important") and the potential for feelings of guilt or responsibility if harm occurs as a result of MMR vaccination (62\% "very important").

\section{Information needs for decision making}

Respondents who were "leaning towards" MMR vaccination after using the decision aid were more likely to feel that they knew their options and that they had enough information to make a
Table 2 Beliefs of 158 respondents about MMR vaccination by their attitudes to vaccination after use of a web based MMR decision aid. Values are numbers (percentages) of respondents rating advantages or disadvantages as "Very important" or answering "Yes" to questions about information needs for decision making

\begin{tabular}{|c|c|c|}
\hline \multirow[b]{2}{*}{ Pros and cons of vaccination and information needs } & \multicolumn{2}{|c|}{$\begin{array}{l}\text { Attitude to MMR } \\
\text { vaccination }\end{array}$} \\
\hline & $\begin{array}{l}\text { "Leaning } \\
\text { toward" } \\
(\mathrm{n}=87)\end{array}$ & $\begin{array}{c}\text { "Undecided" } \\
\text { or "Leaning } \\
\text { away from" } \\
(\mathrm{n}=71)\end{array}$ \\
\hline \multicolumn{3}{|l|}{ Advantages of MMR vaccination } \\
\hline $\begin{array}{l}\text { My child will be better protected from common symptoms of } \\
\text { diseases such as rash, high fever, red and painful eyes, swollen } \\
\text { glands, and joint pain }\end{array}$ & $\begin{array}{r}52 / 83 \\
(63)\end{array}$ & $19 / 63(30)$ \\
\hline $\begin{array}{l}\text { My child will be better protected from the potentially serious } \\
\text { complications of these diseases (such as encephalitis or death) }\end{array}$ & $\begin{array}{r}81 / 83 \\
(98)\end{array}$ & $53 / 63$ (84) \\
\hline $\begin{array}{l}\text { I will not have to take time off work to care for my child if he or } \\
\text { she gets one or more of these diseases }\end{array}$ & $\begin{array}{c}11 / 83 \\
(13)\end{array}$ & $4 / 63$ (6) \\
\hline $\begin{array}{l}\text { My child won't face the restrictions imposed by some schools and } \\
\text { childcare centres that exclude children who have not been } \\
\text { vaccinated }\end{array}$ & $\begin{array}{r}33 / 83 \\
(40)\end{array}$ & 9/63 (14) \\
\hline $\begin{array}{l}\text { My vaccinated child is less likely to pass on diseases to the small } \\
\text { number of children who are unable to be vaccinated for medical } \\
\text { reasons }\end{array}$ & $\begin{array}{c}56 / 82 \\
(68)\end{array}$ & $16 / 63(25)$ \\
\hline
\end{tabular}
reasons

\section{Disadvantages of MMR vaccination}

My child may have some localised swelling where he or she received the injection, have a non-infectious rash, mild cold and flu-like symptoms, or a fever 5-12 days after the vaccination

\begin{tabular}{lccc}
\hline My child may be the 1 in a million children who experiences a & $43 / 75$ & $49 / 63$ (78) \\
serious complication such as a severe allergic reaction or & $(57)$ &
\end{tabular}
serious complication such as a severe allergic reaction or encephalitis

If my child experiences a severe complication I may feel guilty or $\quad 37 / 74 \quad 47 / 61$ (77) responsible for getting him or her vaccinated

Even though the association between MMR and bowel disease and $\quad 20 / 75 \quad 49 / 63$ (78) autism has been disproved, I might feel some concern about these diseases and vaccination

If I choose to vaccinate my child I may be socially ostracised by $\quad 2 / 75$ (3) $5 / 62$ (8) friends, family, or members of my cultural or religious group who do not agree with vaccination

Information needs for decision making

\begin{tabular}{lcc}
\hline Do you know what options are available to you? & $\begin{array}{r}74 / 81 \\
(91)\end{array}$ & $51 / 65$ (78) \\
\hline Do you know which advantages of MMR vaccination are most & $\begin{array}{c}81 / 81 \\
(100)\end{array}$ & $59 / 64$ (92) \\
important to you? & $80 / 81$ & $62 / 65$ (95) \\
\hline Do you know which disadvantages of MMR vaccination are most & $(99)$ & \\
$\quad$ important to you? & $67 / 81$ & $32 / 66$ (48) \\
\hline Do you feel that you have enough information to make decision & $(83)$ & \\
about whether to vaccinate your child with MMR? &
\end{tabular}

about whether to vaccinate your child with MMR?

Denominators vary because respondents did not answer all the questions.

decision (table 2). Of those who remained undecided or were leaning away from vaccination, most $(78 \%)$ said that they knew their options, but $52 \%$ still felt that they didn't have enough information to make a decision or remained unsure. Among all respondents, 32/147 (22\%) remained negative toward vaccination despite feeling well informed.

\section{Discussion}

This pilot study shows that an evidence based decision aid significantly improved parental attitudes towards MMR vaccination. It also shows that those respondents who remained undecided or negative towards vaccination after using the aid were more likely to have concerns about adverse reactions to the vaccine and residual concerns about autism and bowel disease despite a balanced presentation of the evidence. Valuing protection against the common symptoms of measles, mumps, and rubella and feeling well informed were factors in having positive beliefs about MMR vaccination.

Internet based recruitment makes it difficult to estimate how representative our respondents were of the general population 


\section{Research}

of those questioning MMR. However, $61 \%$ of those stating their initial preferences were either "leaning away from" or "undecided about" MMR vaccination, indicating that the aid was successful in attracting the target audience. The large number of respondents from other countries where the site was not promoted indicates the potential for interactive decision aids to have a public health impact beyond the intended local audience. The high hit rate for the aid indicates strong interest and activity on the internet.

The findings indicate that many users of our decision aid had attitudes inconsistent with the best available evidence. Even after completing the decision aid, $50 \%$ of respondents cited the (unsupported) association with autism as "very important" to them in deciding about MMR vaccination. In addition, 62\% reported the potential for feelings of guilt or responsibility if harm occurs as a very important disadvantage of MMR vaccination. This supports previous findings that parental decisions about childhood immunisation can be more strongly influenced by perceived responsibility and anticipatory regret than by a numerical assessment of the risks and benefits of immunisation. $^{14}$ It also supports findings that parents withhold vaccinations because a risk from a known disease may be more acceptable than a smaller risk of ambiguous or unknown consequences. ${ }^{16}$

\section{Limitations of study}

Because of the nature of the internet and the decision aid itself, users were able to access all parts of the aid without completing each section and were not compelled to provide their demographic details. Some users may have felt uncomfortable leaving such information on the website because of concerns over confidentiality. As a result, there is potential for selection bias from the low response rate. This may also have been due to the length of the aid, reflecting the difficulty of providing sufficiently comprehensive information to cover the main risks and benefits of MMR vaccine without being onerous to complete.

In addition, only 52 (84\% of those providing demographic information) of the respondents reported having children of vaccination age: the other respondents' beliefs about vaccination may not be relevant and limit the generalisability of our results. Despite the problems of representativeness, online data collection represents a low cost and low maintenance way to obtain evaluative data and has promise if loss to follow-up can be minimised.

\section{Future work}

Further research is needed to clarify the effectiveness of the decision aid. Firstly, the aid could be adapted to be more interactive (such as response-dependent summary paragraphs) and to provide more in depth scientific evidence (including access to papers from medical journals, critiques of articles, and meta-analyses) that may be layered according to parents' information needs. Then, a randomised controlled trial of the online decision aid might allow the above methodological limitations to be addressed. Given the difficulty some parents have deciding whether to immunise their children with the MMR vaccine, such a study could examine changes in knowledge, decisional conflict, and anxiety. Of interest to government and immunisation advocates would be whether the aid improved the timeliness and completion of MMR vaccination among children of parents who are concerned about the safety of the vaccine.

Contributors: JL, LJT, Peter McIntyre, and Phyllis Butow designed the study. CW and LJT developed the decision aid. Linda MacDougall, Nikki Turner,

\section{What is already known on this topic}

Some parents have strong concerns over an unsupported link between MMR vaccine and autism

Interventions to address parental concerns are largely didactic, and few studies have examined their effectiveness

What this study adds

An online interactive decision aid improved parents attitudes to MMR vaccination

Decision aids have the potential for wider application in providing advice about immunisation

and Helen Petousis-Harris provided advice on MMR decision aids. Crina Belvi, Brynley Hull, and the Centre for Innovation in Professional Health Education (CIPHE) assisted in online development and database setup. JL and LJT planned the analysis. LJT and CW analysed the data. Judy Simpson provided statistical advice. CW, JL, and LJT wrote the paper, and JL is the guarantor for the study.

Funding: NCIRS is an independent research organisation. It is supported by The Commonwealth Department of Health and Ageing, The NSW Department of Health and The Children's Hospital at Westmead.

Competing interests: None declared.

Ethical approval: The Ethics Committee of the Children's Hospital at Westmead gave approval for this research on 6 April 2005.

1 COVER Programme: April to June 2004. Commun Dis Rep CDR Wkly [serial online] 2004;14.

2 Payne D. Ireland's measles outbreak kills two. BMJ 2000;321:197.

3 Raithatha N, Holland R, Gerrard S, Harvey I. A qualitative investigation of vaccine risk perception amongst parents who immunize their children: a matter of public health concern.J Public Health Med 2003;25:161-4.

4 Guillaume LR, Bath PA. The impact of health scares on parents' information needs and preferred information sources: a case study of the MMR vaccine scare. Health Informatics Journal 2004;10:5-22.

5 Sporton RK, Francis S-A. Choosing not to immunize: are parents making informed decisions? Fam Pract 2001;18:181-8.

6 Petts J, Niemeyer S. Health risk communication and amplification: learning from the MMR vaccination controversy. Health Risk Soc 2004;6:7-23.

Hall S, Hobson D, Lowe A, Willis P, eds. Culture, media, language. London: Hutchinson, 1980 .

8 McMurray R, Cheater RM, Weighall A, Nelson C, Schweiger M, Mukherjee S. Managing McMurray R, Cheater RM, Weighall A, Nelson C, Schweiger M, Mukherjee S. Managing controversy through consultation: a qualitative study of comm
around MMR vaccination decisions. Br J Gen Pract 2005;54:520-5.

9 O'Connor AM, Stacey D, Entwistle V, Llewellyn-Thomas H, Rovner D, Holmes-Rovner $\mathrm{M}$, et al. Decision aids for people facing health treatment or screening decisions. Cochrane Database Syst Rev 2003;(2):CD001431.

10 O'Connor AM, Pennie RA, Dales RE. Framing effects on expectations, decisions, and side effects experienced: the case of influenza immunization. J Clin Epidemiol 1997;49:1271-6.

11 Davies P, Chapman S, Leask J. Anti-vaccination activists on the world wide web. Arch Dis Child 2002;87:22-5.

12 Wolfe CR, Sharp LK, Lipsky MS. Content and design attributes of antivaccination web sites. JAMA 2002;287:3245-8.

13 Stacey D, O'Connor AM, Rovner D, Holmes-Rovner M, Tetroe J, Llewellyn-Thomas H, et al. Cochrane inventory and evaluation of patient decision aids. Med Decis Making 2001;21:527.

14 Wroe AL, Turner N, Salkovskis PM. Understanding and predicting parental decisions about early childhood immunizations. Health Psychol 2004;23:33-41.

15 Ritov I, Baron J. Outcome knowledge, regret, and omission bias. Organ Behav Hum Decis Processes 1995;64:119-27.

16 Ritov I, Baron J. Reluctance to vaccinate: omission bias and ambiguity. J Behav Decis Making 1990;3:263-77.

(Accepted 20 September 2005)

doi $10.1136 /$ bmj. 38678.681840 .68

National Centre for Immunisation Research and Surveillance, The Children's Hospital at Westmead, University of Sydney, Locked Bag 4001, Westmead NSW 2145, Australia

Cate Wallace project officer

Julie Leask senior research officer

School of Public Health, University of Sydney

Lyndal J Trevena lecturer

Correspondence to:J LeaskJulieL3@chw.edu.au 